\title{
NUEVAS EDICIONES DE LA OBRA DE GABRIELA MISTRAL PARA PÚBLICO INFANTIL*
}

\author{
NEW EDITIONS OF GABRIELA MISTRAL'S WORK \\ FOR A CHILDREN'S AUDIENCE
}

\section{Yenny Ariz Castillo}

Universidad de Concepción. Concepción, Chile

yennyariz@udec.cl

\begin{abstract}
In duda Alguna, las metodologías empleadas en la enseñanza primaria y los criterios para escoger las lecturas de los estudiantes fueron objeto de reflexión para Gabriela Mistral, quien colaboró con publicaciones diseñadas para niños, y habló, entre otros temas, de la importancia de las ilustraciones y de los relatos como método de enseñanza ${ }^{1}$. Atendiendo a estas inquietudes de la autora, así como también aportando a la difusión de su obra, diversos estudiosos chilenos han compilado textos de Mistral en prosa y en verso, que se editaron en atractivos formatos para el público infantil.
\end{abstract}

En efecto, durante los últimos tres años se han publicado diversas selecciones de Mistral ilustradas para niños. Es el caso de la antología de Ana María Cuneo y Mayú Lira, quienes seleccionaron veinticinco poemas de Ternura y los compilaron en El regalo de la abuela. Poemas de Gabriela

* Publicación que surge del Proyecto Fondecyt Postdoctoral No 3150189 , titulado "La poesía póstuma de Gabriela Mistral: El yo poético ante el 'sueño maravilloso", periodo 2015-2016.

${ }^{1}$ Antes de publicar rondas y canciones de cuna en Ternura (1924), la autora escribe cuentos escolares y poemas para los Libros de Lectura del profesor Manuel Guzmán Maturana, destinados a la enseñanza de las escuelas de Chile (Quezada, 2009: 748). Con respecto a la importancia de las ilustraciones y de amenizar las materias a partir del relato, véase el texto en prosa "Contar" [1929] en el volumen Magisterio y Niño, compilado por Roque Esteban Scarpa (Mistral, 1999 [1929], pp. 94-97). 
Mistral (Ediciones de la Universidad Católica de Chile, 2012), libro ilustrado por Antonia Herrera y María Elisa Soto-Aguilar con motivos de abuelas sonrientes, danzando o de paseo con sus nietos.

En un lenguaje sencillo y ameno, en las primeras páginas de El regalo de la abuela se explica la elección de estos poemas (9-12). A juicio de las compiladoras, el segundo poemario de Mistral es una obra con la capacidad de "contar" a través de los versos, lo que remite a la configuración de "La cuenta-mundo", imagen central del homónimo poema de Ternura, que fue escogido para abrir esta antología infantil.

La intención principal de El regalo de la abuela es demostrar la vigencia de la poesía de Mistral e iniciar a los infantes en la lectura comprensiva y creativa de los textos poéticos; en este sentido, las editoras comentan que los métodos convencionales de enseñanza de la poesía no apuntan al goce de la lectura, sino al aprendizaje de elementos técnicos que más bien distancian a las nuevas generaciones de las riquezas del lenguaje poético.

Las compiladoras se presentan como "abuelas", recuperando de esta manera la tradicional figura de los abuelos contadores de relatos. Por cierto que la principal "Cuenta-mundo" del volumen es Mistral, de quien las editoras dicen que "su tarea de 'contar el mundo' e interpretarlo no finalizó nunca”, en tanto jamás dio por terminado el Poema de Chile (73).

Algunos poemas antologados son presentados en breves introducciones con el fin de motivar la lectura; en estos preámbulos se entregan datos biográficos, como la estadía de Mistral en México (48), que contextualiza el fragmento compilado del poema "Cajita de Olinalá" (49), y las lecturas bíblicas de la poeta junto a su abuela Isabel Villanueva (27), dato que precede al poema "El establo" (29). La imagen de Mistral leyendo con su abuela refleja, además, la propuesta de la antología.

Seis poemas son seguidos por comentarios de las editoras con acertadas acotaciones sobre el lenguaje poético y los temas del texto en particular. Asimismo, estas reflexiones, denominadas "Comentario de la abuela", incitan el diálogo de los lectores sobre lo sugerido en el poema; por ejemplo, el comentario a "El papagayo" finaliza con la pregunta "¿cómo podríamos actuar cuando somos agredidos?" (21).

Destaco también la reflexión sobre el poema "La pajita" (78-79), en la que se señala la presencia del habla campesina en el lenguaje de Mistral, y se recupera la representación de la poesía a partir de la imagen de la pajita, 
que la poeta desarrollara en su célebre conferencia en Uruguay (1938), a fin de explicar cómo escribía. Es así como los niños pueden acceder, en un lenguaje sencillo, a la significación de la poesía para Mistral.

Las editoras terminan la antología motivando a niños/as y jóvenes a continuar la lectura de poesía, pues "tienen los 'poderes' necesarios para penetrar esos 'disparates maravillosos' de los que habla Gabriela Mistral” (79). Cabe destacar que el libro se acompaña de un DVD que contiene algunos poemas compilados en el volumen con sus respectivos comentarios e ilustraciones.

Una editorial que ha contribuido a difundir los textos mistralianos es Amanuta, la que ha publicado las reescrituras de cuentos de hadas en forma poética realizadas por Mistral en la década de 1920: Blanca Nieve en la casa de los enanos [1925], La Cenicienta [1926], La bella durmiente del bosque [1928], editadas por Amanuta durante el año 2012, y Caperucita roja [1924], que fue publicada por la citada editorial en 2014. La serie forma parte de la colección "Poesía ilustrada" de Amanuta², y ganó el premio "El libro más bello", otorgado por la comisión alemana de la UNESCO y la Fundación de Artes Gráficas de Alemania, según reseña el diario La Tercera (11 de marzo de 2014); el reconocimiento fue entregado a la editorial en la Feria del Libro de Leipzig en marzo de 2014.

Cada poema se dispone en un libro individual con ilustraciones, y, a modo de epílogo, se incluye un comentario crítico del estudioso Manuel Peña Muñoz. En el caso de Blanca Nieve en la casa de los enanos (2012), las ilustraciones pertenecen a Carles Ballesteros. En su comentario sobre el poema, Peña señala que originalmente fue publicado en el suplemento literario del diario El Espectador de Bogotá, el 23 de abril de 1925 (33), y que hasta ese momento, no había sido recogido en antologías de Mistral.

Como Peña apunta, lo que Mistral recrea del cuento de los Grimm es el encuentro en la cabaña del bosque entre los siete enanos y la princesa, a la que llama "Blanca Nieve", a diferencia de la tradición que inmortalizó a la

${ }^{2}$ Dentro de la misma colección, Amanuta publicó Gabriela Mistral. Poemas ilustrados (2013), una selección de veinticinco poemas de Desolación, Tala, Lagar y Lagar II realizada por Cristóbal Joannon, acompañados de las ilustraciones de Bernardita Ojeda. En las páginas finales se encuentra una sucinta biografía de la escritora, en la que se enfatiza su interés por la educación de los niños y la escritura de rondas y canciones de cuna. 
protagonista como "Nieves". El estudioso nota además la semejanza entre la escena en que los enanos reconocen la presencia de un extraño en su hogar y descubren a la niña durmiendo, con el cuento "Ricitos de oro", en el que una familia oso experimenta análoga situación (32-33).

La casa de los enanos está asociada a lo materno, como bien señala Peña, a lo que agrego que las imágenes referidas a la misma configuran un lugar mágico y de ensoñación: "Todo sigue en el silencio / que la casa está encantada" (9), "La niña empuja la puerta: / se le abre como dos alas", (9) "y la paz que hay en los sueños, / en la casa se derrama" (10).

Este ambiente ensoñado redunda en el juego de repeticiones constante del número siete al referirse a los objetos de la casa, y en la configuración de los enanos como espíritus protectores del sueño, quienes hacen dormir a la princesa con una tierna canción de cuna; la niña, que ha contado a los enanos la persecución por parte de su madrastra y del cazador, duerme tranquila mientras sus amigos reiteran que la protegerán de todo mal: “y los enanos te velan / en cerco de siete espadas./ Los duendes de los metales/ te cuidan mejor que tu alma" (31).

La Cenicienta (2012), ilustrada por Bernardita Ojeda, fue publicada originalmente en "Lecturas Dominicales" del diario El Tiempo de Bogotá el 26 de diciembre de 1926, como documenta Peña (33). El estudioso además señala que la poeta sigue la versión de Charles Perrault del cuento, la que a diferencia de la de los hermanos Grimm, relata dos bailes en los que Cenicienta, o la "Encenizada" como la llama Mistral, se reúne con el príncipe.

La poeta nos presenta a las hermanastras y la madrastra metaforizadas como ogresas en el poema, y al hada madrina llamada Esplendor (14) y Resplandor (25). La escena del baile constituye un espacio de sueño y fantasía, que la joven teme arruinar con lo cotidiano: "Cenicienta tiene miedo/ de oírse la propia voz,/ porque está viviendo un sueño/ tan perfecto como Dios" (27).

Antes del baile, el hada sopla el hollín de la niña -y con ello le otorga "vida", en lo que se reconocen resabios bíblicos-, y esta revela su belleza y fragilidad: "Cenicienta va quedando/ desnuda como un jazmín" (15). La mirada del hada la cubre de vestiduras reales, y luego de que está lista para asistir al primer baile, la declara su creación: “-Mi ahijada Cenicienta,/ iacabaste de nacer!" (17).

La desnudez de la niña posee una doble significación en el poema, pues 
si al principio remite a su belleza, en el final del texto se relaciona con su condición de huérfana, lo que es interesante, porque en las versiones tradicionales del cuento la orfandad de Cenicienta se "supera", en tanto el matrimonio implica la restauración del núcleo familiar para la niña. En la versión de Mistral, la condición de desprotección de la muchacha se subraya en el enlace con el príncipe, lo que evidencia el contraste entre los dos jóvenes, reforzado además por los elementos con los que estos se vinculan, sol y tizón: "Y aquella misma mañana/ desposó el príncipe Sol/ a María Cenicienta/ veladora del tizón,/ hija de ninguna madre,/ desnudita hija de Dios...." (30).

En La bella durmiente del bosque (2012), Mistral emplea fórmulas del relato oral y términos del habla campesina para poetizar este conocido cuento de hadas, como destaca Peña en el comentario de rigor (32), lo que es relevante en un cuento en el que la desgracia de la protagonista proviene de una maldición, es decir, de la palabra oral. El texto fue publicado por primera vez en el diario El Gráfico de Bogotá, el 14 de julio de 1928 (33). En la edición de Amanuta, el poema se acompaña con las ilustraciones de Carmen Cardemil.

Llama la atención que la hablante detalle los rasgos del hada que consigue transformar la maldición en un hechizo de sueño; esta es una niña muy pequeña, mientras los seres más imponentes de la escena, la pareja de reyes y las hadas restantes, tiemblan ante la maldición con que el hada malvada ha condenado a la princesa: "Pero un hada que era niña/ levantó su fina voz:/ era un hada pequeñita,/ se llamaba Corazón” (12). Quizás esto puede leerse como un anhelo de demostrar a los pequeños/as que su tamaño no les resta importancia, así como se enseña en la fábula de "El león y el ratón".

El hada Corazón logra "quebrar" el discurso del hada malvada, y en su declaración se entremezcla el cristianismo con el paganismo, esto último, por ser ella una figura de la mitología europea. Al dirigirse al personaje maligno, el hada la confronta: "nos quebraste la alegría,/ y yo quiebro tu traición./ La princesa será herida,/ mas, por gracia del Señor,/ va a dormirse por cien años,/ hasta la hora del amor" (14). Es el poder de Dios quien consigue derrotar el mal, y no la magia.

Una figura destacada en la disposición sintáctica del poema es la enumeración que la poeta utiliza, por ejemplo, al caracterizar a los persona- 
jes, mencionar los dones de las hadas y describir la corte de la princesa; la enumeración se acentúa al combinarse con la anáfora, como cuando los elementos y los seres fueron sucumbiendo ante el hechizo del sueño: "Se durmió la mesa regia/ se durmió el pavón real,/ se durmió el jardín intacto,/ con la fuente y el faisán;/ se durmieron los cien músicos/ y las arpas y el timbal;/ se durmió la que lo cuenta,/ como piedra y sin soñar..." (22).

El hechizo incluye a la hablante, quien juega con las acepciones de sueño al declararse atrapada por él con una intensidad "de piedra", forma coloquial que se entiende como "sueño profundo", pero que no implica la representación fantástica de imágenes al dormir.

La serie de Amanuta finaliza con el poema Caperucita Roja (2014), ilustrado por Paloma Valdivia, y publicado por Mistral en Ternura (1924). Por esta razón, es el más conocido de los cuatro poemas sobre cuentos de hadas. Como indica Peña, la poeta sigue la versión de Charles Perrault del cuento, con un final trágico, que el autor francés recreó como una advertencia a las jóvenes de los peligros de la seducción (30)3.

Por último, la editorial Pehuén, la Fundación Procultura y Plop! Galería editaron en 2014 la serie Reino animal, tres antologías de Mistral destinadas al público infantil. Las tres selecciones fueron realizadas por Pedro Pablo Zegers, quien incluyó textos en prosa y en verso dedicados a los animales. Los textos seleccionados demuestran la sensibilidad de la poeta con respecto a estos seres, y el interés por educar a las nuevas generaciones en la curiosidad, el aprecio y el respeto hacia ellos. Cada libro de la serie contiene además un glosario y fichas con los datos científicos de las especies aludidas.

Los volúmenes Reino animal. Prosa de la tierra, ilustrado por Pati Aguilera, y Reino animal. Prosa del agua y del viento, ilustrado por Raquel Echenique, reúnen, en su mayoría, diversos textos de las "Estampas de animales" de Mistral, las que son breves prosas poéticas que nunca se publicaron en conjunto. Recientemente, Luis Vargas Saavedra compiló veinte de las "Estampas" en Caminando se siembra (2013); en el "Preámbulo" a esta antología, el estudioso indica que gran parte de las "Estampas de animales"

${ }^{3}$ Este poema ha sido abordado por la crítica con antelación, por ejemplo, en el artículo de Jorge Guzmán “Dos poemas de Gabriela Mistral” (1989), en el que el estudioso realiza un análisis semiótico del mismo. 
fueron escritas entre "agosto y diciembre de 1926, tras visitas a los jardines zoológicos de París, Amberes y Marsella" (19), y fueron publicadas en los diarios El Mercurio (Chile) y El Universal (México) durante las décadas de 1920 y 1930 (19).

Para Vargas Saavedra, las "Estampas" trascienden la intención pedagógica, y poseen "independencia estética mediante lirismo, humor y franciscanismo" (19); de esta manera, el experto mistraliano comenta que el ejemplo de Francisco de Asís es el que subyace en estos textos; asimismo, considera a las "Estampas" "prosas de lirismo total", es decir, de intención poética, junto con "Elogios de las materias" y "Motivos de San Francisco" (18).

Como señala Vargas Saavedra, la escritora se refería a sus "Estampas" como "lección bien coloreada de imágenes felices" (18). De esta manera, el objetivo de estos textos es "ilustrar" a cada especie a partir del lenguaje poético. Es así como el gato, "es lento como los grandes relojes" (2014a, p. 11), las focas son "perritas de la arena" (2014b, p. 8); y el perro, "es un olfato feliz" como escribe Mistral en "El perro" (2014a, p. 9), estampa que no se había editado con anterioridad en Chile.

No todas las prosas que se incluyen en la serie Reino animal corresponden a "Estampas de animales"; el texto "Los sapos" (2014c, pp. 47-49) constituye la apreciación estética de una lectura clásica realizada por la poeta. Su título completo es "Los sapos (de Las metamorfosis de Ovidio)", como se puede comprobar en la versión manuscrita del texto digitalizada por la Biblioteca Nacional, fechada entre 1920 y 1921.

Reino animal. Poesía, con ilustraciones de Fito Holloway, sigue el formato de los dos volúmenes comentados; contiene poemas de Ternura, Tala, Lagar y Poema de Chile, lo que permite a los/as niños/as re-descubrir poemas clásicos como "La rata" y "Ocho perritos"; en este último poema, la hablante no solo expresa su deleite por el nacimiento de unos cachorros, sino también su anhelo de ser una "hija de Dios" del reino animal. En este deseo se percibe la doctrina de San Francisco, quien consideraba a los animales nuestros hermanos, pero además se podría postular la creencia en la reencarnación: "y yo querría nacer con ellos./ ¿Por qué otra vez no sería?/ Saltar de unos bananales/ una mañana de maravilla,/ en can, en coyota, en venada; / (...) / hija de Dios, sierva oscura y divina” (23).

Al hojear las páginas de las ediciones mencionadas es posible percibir la 
dedicación con que se ha hecho el trabajo de compilación y de edición, pues se han elegido cuidadosamente los textos y los ilustradores han respondido con profesionalismo al desafío de representar la escritura mistraliana. Es de esperar que las futuras ediciones de Mistral para público infantil mantengan la misma calidad.

\section{Referencias}

Guzmán, J. (1989). Dos poemas de Gabriela Mistral. Acta Literaria, 14, 67-78. S/A. Libros ilustrados de versos de Gabriela Mistral ganan premio de la UNESCO. La Tercera, 11 de marzo de 2014. En http://www.latercera.com/ noticia/cultura/2014/03/1453-569003-9-libros-ilustrados-de-versosde-gabriela-mistral-ganan-premio-de-la-unesco.shtml

Mistral, G. (1920-1921). Los sapos de Las metamorfosis de Ovidio [manuscrito]. Biblioteca Nacional, Legado de Gabriela Mistral, ubicación AEooo1143. En http://www.coleccionesdigitales.cl/view/action/singleViewer.do?dvs $=1447361953647 \sim 951 \& l o c a l e=$ es_ES\&VIEWER_URL=/view/action/singleViewer.do?\&DELIVERY_RULE_ID=10\&search_terms=los\%20sapos\%20 las\%2ometamorfosis\%20ovidio\&adjacency=N\&application=DIGITOOL$3 \&$ frameId $=1 \&$ usePid $1=$ true\&usePid2=true

. (1989) [1938]. "Cómo hago mis versos" Revista Araucaria de Chile, $\mathrm{N}^{\circ}$

45. Disponible en: http://www.blest.eu/cultura/gabriela89.html

. (1999) [1929]. "Contar". Magisterio y Niño (pp. 94-97). Selección de Roque Esteban Scarpa. Santiago: Andrés Bello.

. (2012) [1925]. Blanca Nieve en la casa de los enanos. Ilustraciones de Carles Ballesteros. Comentario crítico de Manuel Peña Muñoz. Santiago: Amanuta.

. (2012) [1926]. La Cenicienta. Ilustraciones de Bernardita Ojeda, Comentario crítico de Manuel Peña Muñoz. Santiago: Amanuta. . (2012) [1928]. La bella durmiente del bosque. Ilustraciones de Carmen Cardemil. Comentario crítico de Manuel Peña Muñoz. Santiago: Amanuta. . (2012). El regalo de la abuela. Poemas de Gabriela Mistral. Lectura y comentarios de Ana María Cuneo y Mayú Lira. Santiago: Ediciones Universidad Católica.

. (2013). Poemas ilustrados. Santiago: Amanuta.

. (2014) [1924]. Caperucita roja. Ilustraciones de Paloma Valdivia. Comentario crítico de Manuel Peña Muñoz. Santiago: Amanuta. . (2014a). Reino animal. Prosa de la tierra. Selección Pedro Pablo Zegers Blachet. Ilustraciones Pati Aguilera. Santiago: Pehuén. 
. (2014b). Reino animal. Prosa del agua y del viento. Selección Pedro Pablo Zegers Blachet. Ilustraciones Raquel Echenique. Santiago: Pehuén. . (2014c). Reino animal. Poesía. Selección Pedro Pablo Zegers Blachet. Ilustraciones Fito Holloway. Santiago: Pehuén.

Quezada, J. (2009). Cronología. Gabriela Mistral a través de su vida. En Poesías Completas (pp. 737-780). Santiago: Andrés Bello.

Vargas Saavedra, L. (2013). Preámbulo. En Caminando se siembra. Prosas inéditas (pp. 13-22). Santiago: Lumen. 